\title{
The role of insulin receptor substrate 2 in hypothalamic and $\beta$ cell function
}

\author{
Agharul I. Choudhury, ${ }^{1}$ Helen Heffron, ${ }^{1}$ Mark A. Smith, ${ }^{2}$ Hind Al-Qassab, ${ }^{1}$ \\ Allison W. Xu, ${ }^{3}$ Colin Selman, ${ }^{1}$ Marcus Simmgen, ${ }^{1}$ Melanie Clements, ${ }^{1}$ Marc Claret, ${ }^{1}$ \\ Gavin MacColl, ${ }^{1}$ David C. Bedford,1 Kazunari Hisadome, ${ }^{2}$ Ivan Diakonov, ${ }^{1}$ \\ Vazira Moosajee, ${ }^{4}$ Jimmy D. Bell, ${ }^{4}$ John R. Speakman, ${ }^{5}$ Rachel L. Batterham, ${ }^{1}$ \\ Gregory S. Barsh, ${ }^{3}$ Michael L.J. Ashford, ${ }^{2}$ and Dominic J. Withers ${ }^{1}$ \\ ${ }^{1}$ Centre for Diabetes and Endocrinology, Rayne Institute, University College London, London, United Kingdom. 2Neurosciences Institute, \\ Division of Pathology and Neuroscience, Ninewells Hospital and Medical School, University of Dundee, Dundee, United Kingdom. \\ ${ }^{3}$ Departments of Genetics and Pediatrics, Stanford University School of Medicine, Stanford, California, USA. 4Molecular Imaging Group, \\ Medical Research Council Clinical Sciences Centre, Faculty of Medicine, Imperial College London, Hammersmith Hospital Campus, London, United Kingdom. \\ ${ }^{5}$ Aberdeen Centre for Energy Regulation and Obesity (ACERO), School of Biological Sciences, University of Aberdeen, Aberdeen, United Kingdom.
}

Insulin receptor substrate 2 (Irs2) plays complex roles in energy homeostasis. We generated mice lacking Irs 2 in $\beta$ cells and a population of hypothalamic neurons (RIPCreIrs $2 \mathrm{KO}$ ), in all neurons (NesCreIrs2KO), and in proopiomelanocortin neurons (POMCCreIrs2KO) to determine the role of Irs2 in the CNS and $\beta$ cell. RIPCreIrs $2 K O$ mice displayed impaired glucose tolerance and reduced $\beta$ cell mass. Overt diabetes did not ensue, because $\beta$ cells escaping Cre-mediated recombination progressively populated islets. RIPCreIrs $2 \mathrm{KO}$ and NesCreIrs $2 \mathrm{KO}$ mice displayed hyperphagia, obesity, and increased body length, which suggests altered melanocortin action. POMCCreIrs $2 K O$ mice did not display this phenotype. RIPCreIrs2KO and NesCreIrs2KO mice retained leptin sensitivity, which suggests that CNS Irs2 pathways are not required for leptin action. NesCreIrs $2 \mathrm{KO}$ and POMCCreIrs $2 \mathrm{KO}$ mice did not display reduced $\beta$ cell mass, but NesCreIrs $2 \mathrm{KO}$ mice displayed mild abnormalities of glucose homeostasis. RIPCre neurons did not express POMC or neuropeptide Y. Insulin and a melanocortin agonist depolarized RIPCre neurons, whereas leptin was ineffective. Insulin hyperpolarized and leptin depolarized POMC neurons. Our findings demonstrate a critical role for IRS2 in $\beta$ cell and hypothalamic function and provide insights into the role of RIPCre neurons, a distinct hypothalamic neuronal population, in growth and energy homeostasis.

\section{Introduction}

Insulin regulates peripheral energy homeostasis by acting on multiple tissues to control carbohydrate, lipid, and protein metabolism (1). Gene targeting in mice has shown that $\beta$ cell deletion of the insulin receptor causes reduced first-phase insulin release, reduced $\beta$ cell insulin content, and progressive deterioration in glucose tolerance (2). Early studies of the effects of insulin in the CNS demonstrated a role for intracerebroventricularly administered insulin in the control of food intake and body weight (3). Mouse brain insulin receptor deletion causes mild hyperphagia and adiposity in female mice, diet-sensitive obesity, and defects in reproductive function (4). Results from studies in which insulinomimetics and insulin receptor antisense were centrally administered also support a role for CNS insulin signaling in energy homeostasis regulation $(5,6)$. Insulin signaling mechanisms therefore regulate $\beta$ cell and CNS function, but it is unclear which postreceptor compo-

\footnotetext{
Nonstandard abbreviations used: AgRP, agouti-related protein; DBA, Dolichos biflorus agglutinin; DIG, digoxigenin; ICC, immunocytochemistry; Irs, insulin receptor substrate; Irs 2 lox mice, mice with a floxed allele of Irs $2 ; \mathrm{ISH}$, in situ hybridization; $\alpha \mathrm{MSH}, \alpha$ melanocyte-stimulating hormone; MTII, melanotan II; NesCreIrs $2 \mathrm{KO}$ mice, mice lacking Irs2 in nestin Cre-expressing cells; NPY, neuropeptide Y; POMC, proopiomelanocortin; POMCCreIrs $2 \mathrm{KO}$ mice, mice lacking Irs 2 in POMC-expressing cells; RIP, rat insulin 2 promoter; RIPCre mice, mice expressing Cre under the control of the rat insulin 2 promoter; RIPCreIrs $2 \mathrm{KO}$ mice, mice lacking Irs 2 in $\beta$ cells and a poorly characterized population of hypothalamic neurons; TTX, tetrodotoxin; $\mathrm{VMH}$, ventromedial hypothalamus.

Conflict of interest: The authors have declared that no conflict of interest exists.

Citation for this article: J. Clin. Invest. 115:940-950 (2005)

doi:10.1172/JCI200524445.
}

nents mediate which physiological effects and, in the case of the CNS, which neuronal populations are involved. It is also unclear how insulin signaling components interact with other molecules involved in energy homeostasis, such as leptin.

Insulin receptor substrate (Irs) proteins lie downstream of the activated insulin and type 1 insulin-like growth factor receptor (7). Gene targeting studies have revealed distinct physiological roles for the 4 major Irs proteins (7). Mice lacking Irs 1 display profound growth retardation and insulin resistance but, due to $\beta$ cell compensation, do not develop diabetes $(8,9)$. Irs3- and Irs4-null mice have minimal metabolic, endocrine, and growth phenotypes (7). In contrast, mice lacking Irs 2 develop diabetes due to insulin resistance and pancreatic $\beta$ cell dysfunction (10). These studies have suggested that Irs 2 is the major mediator of the metabolic effects of insulin and have identified a novel role for Irs 2 signaling in the maintenance of $\beta$ cell mass. Irs 2 signaling also plays complex roles in neuroendocrine function. Female Irs2-null mice are infertile, hyperphagic, and develop obesity (11). Irs2-null mice are reported to be leptin resistant (12), which suggests that Irs2 acts as a point of convergence for leptin and insulin signaling.

It has recently been reported that mice lacking Irs 2 in both pancreatic $\beta$ cells and a poorly defined hypothalamic neuronal population (generated using a rat insulin 2 promoter Cre [RIPCre] recombinase transgene) display reduced islet mass, impaired glucose tolerance, and hypothalamic dysfunction $(13,14)$. Unlike mice with global deletion of Irs2, these mice did not develop progressive diabetes. One study (13) reported that they displayed a hypothalamic phenotype suggesting melanocortin dysfunction, proposed that RIPCre neurons 


\section{A}

Targeting

vector

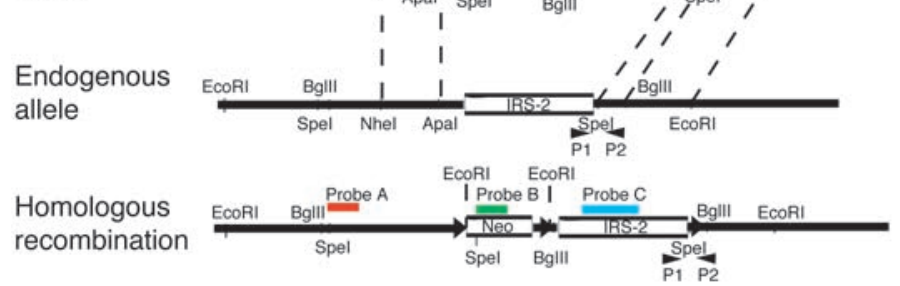

Cre-mediated recombination Type 2 deletion

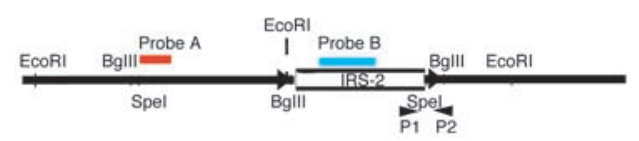

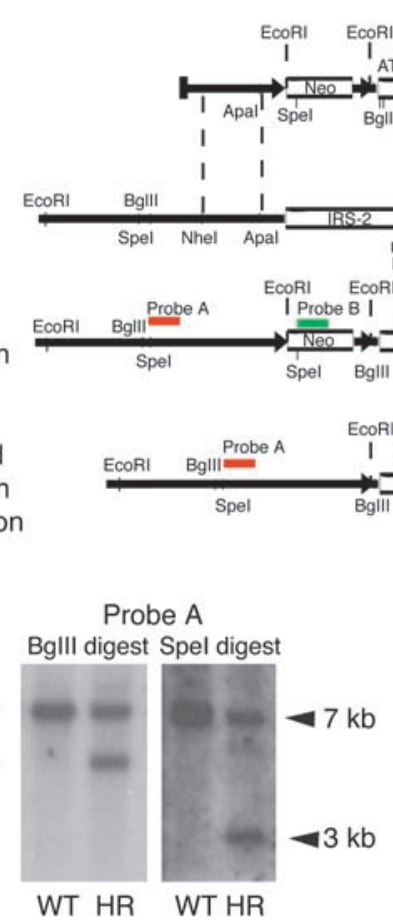

C Probe $\mathrm{B}$ EcoRI digest

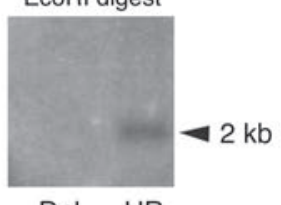

Del HR
D Probe $\mathrm{C}$ EcoRI digest

WT

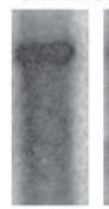

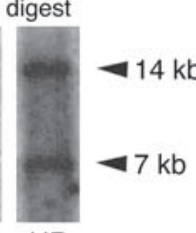

HR
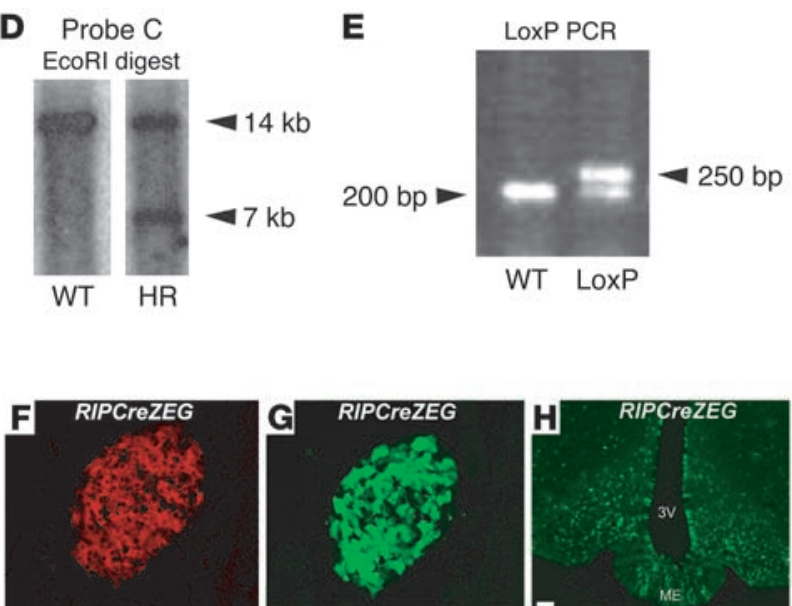

$\alpha$ Insulin

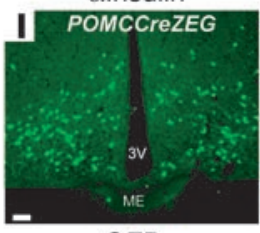

GFP

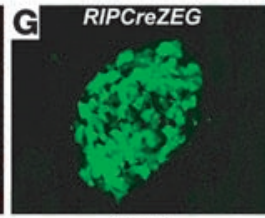

GFP

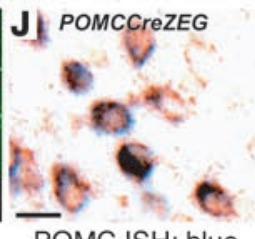

POMC ISH: blue GFP ICC: brown

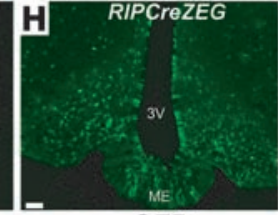

GFP

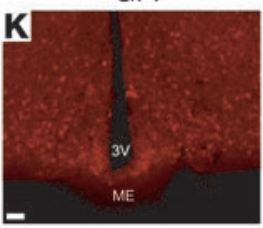

$\alpha$ lrs2

Figure 1

Generation of Irs2flox mice and characteristics of RIPCre and POMCCre mice. (A) Schema of targeting construct design, simplified restriction map of the Irs2 locus, the locus after homologous recombination and the deletion of neomycin cassette (Neo), and Southern blotting and PCR genotyping strategies used to identify these events. External probe A was used to identify homologous recombination (HR), probe B to detect the selection cassette, and probe $\mathrm{C}$ to detect the coding region of Irs2. HSV-tk, herpes simplex virus thymidine kinase. (B) Southern blot analysis with probe A demonstrating homologous recombination after targeting. ( $\mathbf{C}$ and $\mathbf{D})$ Southern blots using probe $\mathrm{B}$ after Cre-mediated recombination demonstrating deletion (Del) of the neomycin cassette and using probe $\mathrm{C}$ to demonstrate retention of Irs2 coding region confirming type 2 recombination. (E) PCR analysis with primers $\mathrm{P} 1$ and P2 of HR clone that has lost the neomycin cassette but retained the loxP site downstream of the Irs2 coding region. $(\mathbf{F}-\mathrm{H})$ We examined Cre expression in RIPCre mice by analyzing GFP expression in pancreatic sections costained with insulin and hypothalamic sections from RIPCreZEG mice. (I) We examined Cre expression in POMCCre mice by analyzing hypothalamic sections from POMCCreZEG mice. (J) Combined ISH for POMC and ICC for GFP was performed in POMCCreZEG mice to confirm Cre expression in POMC neurons. (K) Immunohistochemistry for IRS2 (red) was performed in hypothalamic sections from POMCCreZEG mice. Scale bars: $50 \mu \mathrm{m}(\mathbf{H}, \mathbf{I}$, and K) and $10 \mu \mathrm{m}(\mathrm{J})$. $3 \mathrm{~V}$, third ventricle; $\mathrm{ME}$, median eminence.

are proopiomelanocortin (POMC) neurons, and noted $\beta$ cell recovery with time through an undetermined mechanism. Another study (14) demonstrated reduced islet mass, obesity, and leptin resistance but did not report other features of hypothalamic dysfunction or long-term analysis of islet function. Consequently, these studies have raised a number of critical but unanswered questions (15). In particular it is unclear (a) why there is a relative recovery of the $\beta$ cell phenotype; (b) what role the CNS plays in the $\beta$ cell phenotype and the impairment of glucose homeostasis; (c) what is the role of Irs2 in leptin action; and (d) what are the identity and characteristics of the hypothalamic neuronal population involved (15).

To address these questions, we generated mice lacking Irs 2 in specific cell types: RIPCreIrs $2 K O$ mice, lacking Irs 2 in $\beta$ cells and a poorly characterized population of hypothalamic neurons; NesCreIrs $2 \mathrm{KO}$ mice, lacking Irs2 in all neurons but not the endocrine pancreas; and POMCCreIrs $2 \mathrm{KO}$ mice, lacking Irs 2 in POMCCre-expressing cells.

\section{Results}

Generation of mice with a floxed allele of Irs2. We generated mice with a floxed allele of Irs2 (Irs2lox mice) to permit its deletion in different cell types and tissues (Figure 1, A-E). Irs2lox mice, when bred to homozygosity, were phenotypically indistinguishable from wild-type animals and displayed normal Irs2 expression (data not shown).

Using 3 Cre recombinase transgenic lines, we generated RIPCreIrs $2 K O$, NesCreIrs $2 K O$, and POMCCreIrs $2 K O$ mice. We also intercrossed RIPCre and POMCCre mice with ZEG (16) and Rosa26lacZ (17) indicator mice on both wild-type and Irs2lox/lox backgrounds. This allowed identification of cell types in which recombination occurred and permitted Irs2 deletion and GFP or lacZ expression in the same cell types. RIPCreZEG mice expressed GFP in pancreatic islets, hypothalamic structures such as the arcuate, lateral, and ventromedial hypothalamus (VMH), and a discrete population of forebrain neurons (Figure 1, F-H, and data not shown). In POMCCreZEG mice, GFP expression was found in a discrete population of arcuate nucleus neurons (Figure 1I). Combined in situ hybridization (ISH) and immunocytochemistry (ICC) studies demonstrated colocalization of GFP and POMC (Figure 1J) in more than $90 \%$ of cells examined, which indicated that most POMC neurons also expressed functional Cre recombinase. No GFP expression was found in pancreatic $\beta$ cells (data not shown). NesCre mice delete in neurons but not pancreatic endocrine cells (18) and have been used to manipulate insulin signaling in the CNS (4). 


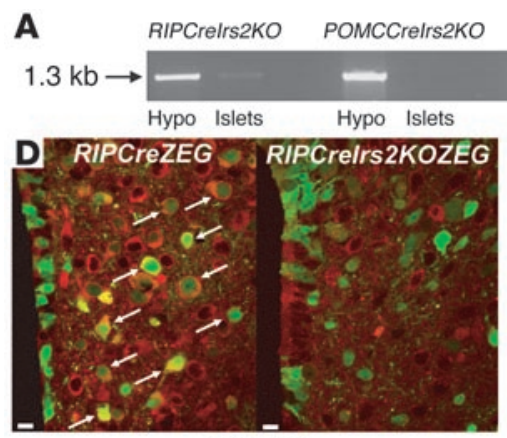

Irs2: red RIPCreGFP: green

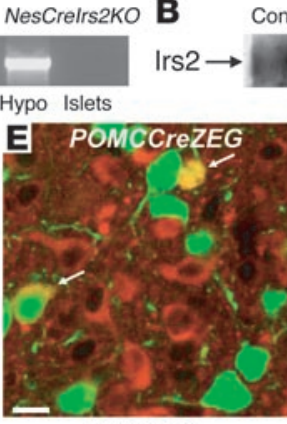

Irs2: red POMCCreGFP: green
Control RIPCrelrs2KO
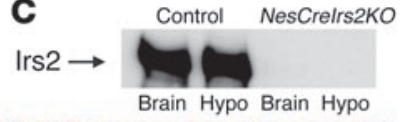

Islets Brain Hypo Brain Hypo

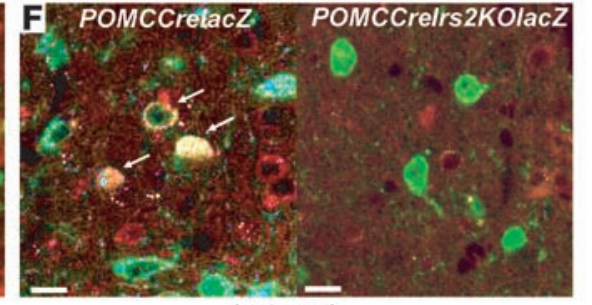

Irs2: red

POMCCrelacZ: green

\section{Figure 2}

Analysis of deletion of Irs2 in islets and hypothalami from RIPCrelrs2KO, POMCCrelrs $2 K O$, and NesCrelrs2KO mice. (A) We performed PCR analysis to detect recombination of the Irs2 locus in DNA from islets and hypothalami (hypo) of control and knockout mice. The presence of a 1.3-kb PCR product indicates recombination and deletion of the Irs2 gene. (B and C) Western blot analysis of Irs2 in islets from control and RIPCrelrs2KO mice (B) and whole brain and hypothalamic lysates from control and NesCrelrs2KO mice (C). (D) Immunofluorescence analysis for Irs2 expression in the hypothalami of RIPCreZEG and RIPCrelrs2KOZEG mice. Colocalization of GFP (green) and Irs2 (red) is seen in RIPCreZEG mice (indicated by white arrows) and no colocalization in RIPCrelrs2KOZEG mice. RIPCreGFP, GFP expression in RIPCre cells. (E) Colocalization of POMCCre expression and Irs2 in POMCCreZEG mice. (F) Colocalization of POMCCre expression and Irs2 in POMCCrelacZ mice and no colocalization of GFP and Irs2 in POMCCrelrs2KOlacZ mice. Confocal images of representative arcuate nucleus fields are shown in D-F. Scale bars: $10 \mu \mathrm{m}$.

Irs2 expression was found in pancreatic islets and in the arcuate, the $\mathrm{VMH}$, and the paraventricular nucleus (Figure $1 \mathrm{~K}$ and Figure $2 \mathrm{~B}$ and data not shown).

To confirm deletion of Irs 2 in the RIPCreIrs $2 K O$, NesCreIrs $2 K O$, and POMCCreIrs $2 K O$ mice, we analyzed recombination of the Irs2flox allele by PCR in islet and hypothalamic DNA. In 4-weekold mice, the recombined allele was detected in both tissues in RIPCreIrs $2 K O$ mice (Figure 2A) but only in the hypothalami of NesCreIrs $2 \mathrm{KO}$ and POMCCreIrs $2 \mathrm{KO}$ mice (Figure 2A). Immunoprecipitation and Western blotting confirmed the lack of Irs2 expression in isolated islets from RIPCreIrs $2 \mathrm{KO}$ and in either whole brain or hypothalamic lysates from NesCreIrs $2 \mathrm{KO}$ mice (Figure 2, B and C). ICC analysis of RIPCreZEG mice demonstrated Irs 2 colocalization with GFP in some but not all hypothalamic arcuate neurons (Figure 2D, left panel). In RIPCreIrs2KOZEG mice, there was no colocalization of Irs2 and GFP, which confirmed Irs2 deletion in RIPCre neurons (Figure 2D, right). Irs2 expression remained in other hypothalamic neurons. Analysis of Irs2 expression in POMCCreZEG mice demonstrated colocalization of Irs2 with GFP in some POMC neurons (Figure 2E). Irs2 deletion was confirmed in POMCCreIrs $2 \mathrm{KOlacZ}$ mice (we were unable to breed $P O M C C r e I r s 2 K O Z E G$ mice), but Irs2 expression remained in other hypothalamic arcuate neurons (Figure 2F). Normal Irs2 expression was detected in muscle, liver, adipose, and other tissues in mice of all 3 lines (data not shown).

Glucose homeostasis in RIPCreIrs $2 \mathrm{KO}$, NesCreIrs $2 \mathrm{KO}$, and POMCCreIrs $2 K O$ mice. In 4-week-old male RIPCreIrs $2 K O$, NesCreIrs $2 \mathrm{KO}$, and POMCCreIrs $2 \mathrm{KO}$ mice, fasting blood glucose levels were indistinguishable from those of control animals (data not shown). At 12 weeks of age, when male Irs2-null mice are diabetic, RIPCreIrs $2 K O$ mice had higher fasting blood glucose levels than control mice, and glucose tolerance tests revealed defective glucose disposal (Figure 3, A and B). However, the elevation in fasting blood glucose levels was modest, and thus RIPCreIrs $2 \mathrm{KO}$ mice did not display the overt diabetes and catabolic state that Irs2-null mice develop. Fasting glucose levels were also elevated in NesCreIrs $2 \mathrm{KO}$ mice, and glucose tolerance was mildly impaired (Figure 3, A and C). RIPCreIrs $2 \mathrm{KO}$ and NesCreIrs $2 \mathrm{KO}$ mice at 6 months of age and older did not develop markedly elevated fasting blood glucose levels but remained glucose intolerant (Figure 3D and data not shown). In contrast, fasting glucose levels and glucose tolerance were equivalent to those of controls in POMCCreIrs $2 \mathrm{KO}$ mice at 12 weeks and older (Figure 3A and data not shown).

At 12 weeks, RIPCreIrs $2 K O$ and NesCreIrs $2 K O$ mice, but not $P O M C C r e I r s 2 K O$ mice, displayed fasting hyperinsulinemia compared with control animals, which suggests development of insulin resistance (Figure 3E). At 6 months, both RIPCreIrs $2 K O$ and $\mathrm{Nes}$ CreIrs $2 \mathrm{KO}$ mice remained hyperinsulinemic (data not shown). At 4 weeks, when there was a 50\% reduction in $\beta$ cell mass in Irs 2 -null mice (10), no decrease in $\beta$ cell mass was seen in RIPCreIrs 2 KO compared with control animals (data not shown). However, by 12 weeks, RIPCreIrs $2 \mathrm{KO}$ mice had a $40 \%$ reduction in $\beta$ cell mass compared with control mice (Figure $3 \mathrm{~F}$, left), consistent with the deterioration in glucose homeostasis at this age. In contrast, 12 -weekold NesCreIrs $2 \mathrm{KO}$ mice exhibited an increased $\beta$ cell mass, evidence of a compensatory response to insulin resistance (Figure 3F, left). $P O M C C r e I r s 2 K O$ did not display altered $\beta$ cell mass compared with age-matched controls (data not shown).

To investigate the preservation of glucose homeostasis compared with Irs2-null mice, we examined $\beta$ cell mass in 9-monthold RIPCreIrs $2 \mathrm{KO}$ mice. RIPCreIrs $2 \mathrm{KO}$ mice had a reduced islet area compared with control animals (Figure 3F, right), but the area had increased from that seen in 12-week-old RIPCreIrs $2 \mathrm{KO}$ mice, which suggests partial recovery in $\beta$ cell mass (Figure $3 \mathrm{~F}$, right).

Hypothalamic function in RIPCreIrs $2 K O$, NesCreIrs $2 K O$, and POMCCreIrs $2 \mathrm{KO}$ mice. RIPCreIrs $2 \mathrm{KO}$ and NesCreIrs $2 \mathrm{KO}$ mice displayed increased body weight compared with control mice starting around 4-5 weeks of age. By 12 weeks of age, they were $20 \%$ heavier than control animals (Figure 4A). RIPCreIrs $2 \mathrm{KO}$ and NesCreIrs $2 \mathrm{KO}$ mice were significantly longer than control mice (Supplemental Figure 1; supplemental material available online with this article; doi:10.1172/JCI200524445DS1). MRI scanning performed at 16 
A

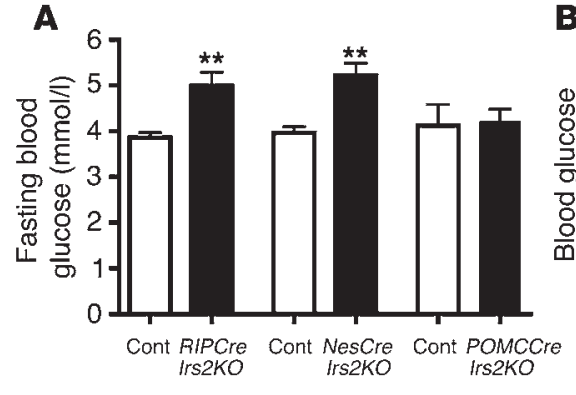

B
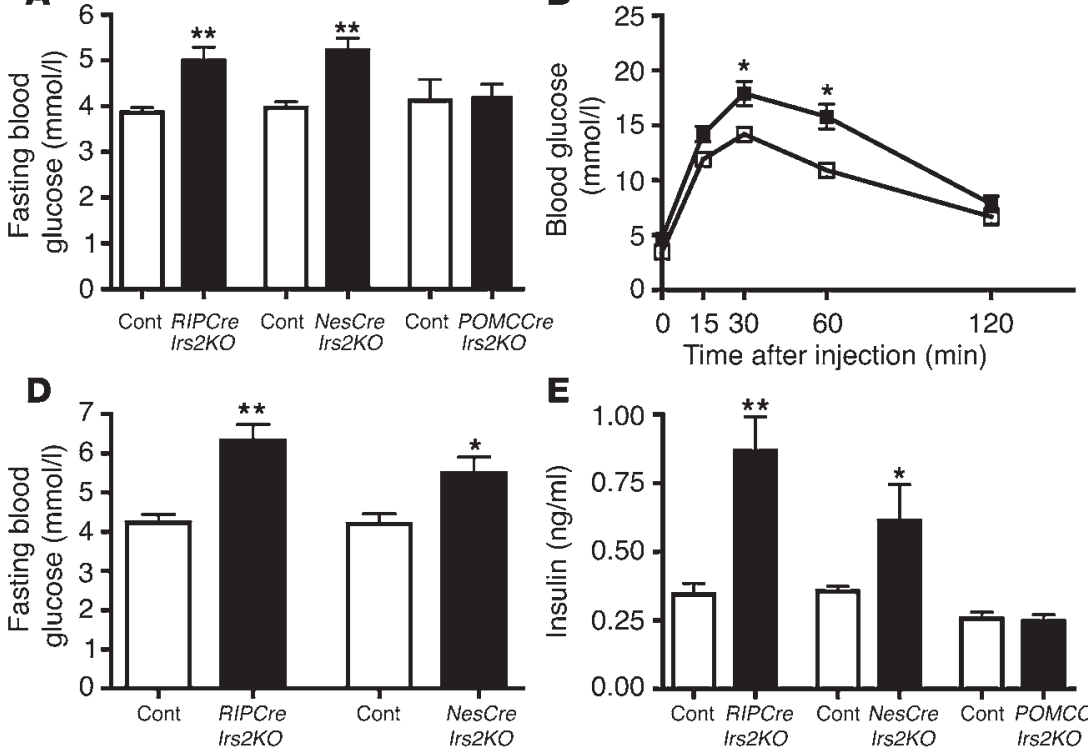

$\mathbf{E}$

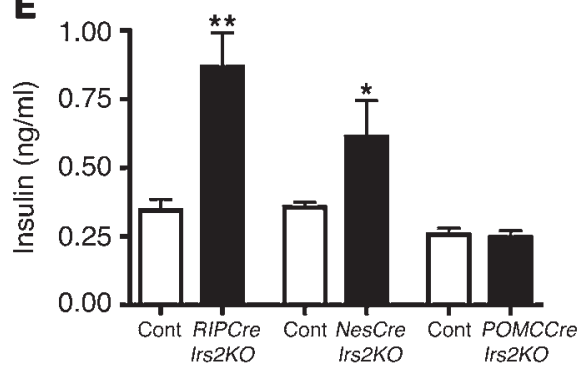

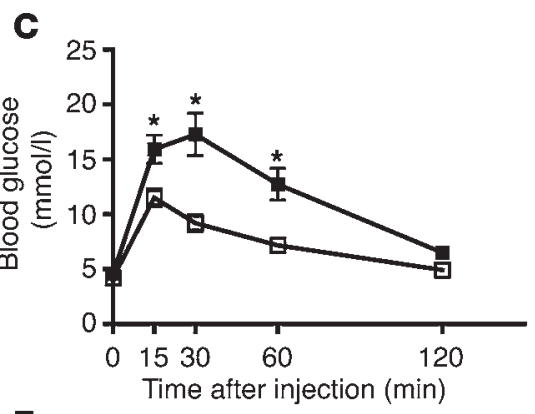

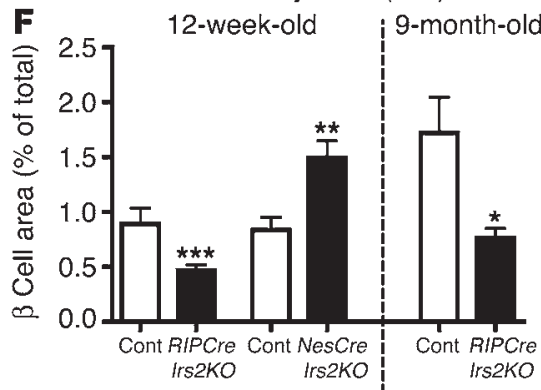

Figure 3

Glucose homeostasis in RIPCrelrs2KO, NesCrelrs2KO, and POMCCrelrs2KO mice. (A) Fasting blood glucose levels of 12-week-old male mice of the indicated genotypes were measured after a 16-hour overnight fast. (B). Glucose tolerance tests were performed on 12-weekold male RIPCrelrs2KO (filled squares) and control mice (open squares). (C) Glucose tolerance tests were performed on 12-week-old male NesCrelrs2KO (filled squares) and control mice (open squares). (D) Fasting blood glucose levels of 6-month-old male mice of the indicated genotypes were measured after a 16-hour overnight fast. (E) Fasting blood insulin levels of 12-week-old male mice of the indicated genotypes were measured after a 16-hour overnight fast. Data in A-E represent the mean \pm SEM for 8-10 animals of each genotype. (F) We calculated the percentage of the total pancreatic area occupied by $\beta$ cells in 12-week-old male mice of the indicated genotypes using insulin-stained pancreatic sections. The right side shows data for 9-month-old RIPCrelrs $2 K O$ and control mice. Four pancreata were analyzed per genotype at each time point, and for each pancreas, 4 sections were analyzed. The data presented are mean \pm SEM for 4 mice of each genotype. ${ }^{\star} P<0.05$, ${ }^{* *} P<0.01$, and ${ }^{* * *} P<0.001$. Cont, control.

weeks showed increased fat mass that was more significant in NesCreIrs $2 \mathrm{KO}$ mice (Figure 4B). At 12 weeks, 24-hour food consumption was greater in both RIPCreIrs $2 \mathrm{KO}$ and NesCreIrs $2 \mathrm{KO}$ mice than in control animals (Figure 4C). In contrast, analysis of resting metabolic rate, core temperature, and activity revealed no differences between RIPCreIrs $2 K O$ or NesCreIrs $2 K O$ mice and control animals (Supplemental Table 1). Furthermore POMCCreIrs $2 K O$ mice did not display increased body weight (Figure 4A), were of the same length as controls (Supplemental Figure 1), and did not eat more than control mice (Figure 4C).

At 12 weeks of age when RIPCreIrs $2 \mathrm{KO}$ and NesCreIrs $2 \mathrm{KO}$ mice displayed marked obesity, leptin levels were significantly elevated in these mice but not in POMCCreIrs2KO mice (Figure 4D). We administered leptin $(5 \mathrm{mg} / \mathrm{kg})$ peripherally for 3 days to acclimatized 6-week-old mice. This treatment inhibited cumulative 3 -day food intake in control animals by $20 \%$ compared with vehicle-treated animals (Figure 4, E and F). RIPCreIrs $2 \mathrm{KO}$ and NesCreIrs $2 \mathrm{KO}$ mice, despite being hyperphagic, also responded to leptin treatment with a $20 \%$ decrease in cumulative food intake (Figure 4, E and F). The reduction in food intake was accompanied in control, RIPCreIrs $2 \mathrm{KO}$, and NesCreIrs $2 \mathrm{KO}$ mice by a significant reduction in body weight (Figure $4 \mathrm{G}$ ). To further investigate the temporal development of the feeding phenotype, we measured leptin levels and food intake in 5-week-old male RIPCreIrs $2 \mathrm{KO}$ mice. At this age, RIPCreIrs $2 \mathrm{KO}$ mice were hyperphagic but did not display hyperleptinemia (Figure $4 \mathrm{H})$. Findings for NesCreIrs $2 \mathrm{KO}$ mice were similar (data not shown).
Characterization of $\beta$ cell recovery in RIPCreIrs $2 \mathrm{KO}$ mice. Our studies and others $(13,15,19)$ raise the question of the mechanism for the relative recovery of the $\beta$ cell mass in RIPCreIrs $2 K O$ mice with age. Analysis of 4-week-old RIPCreIrs2KOZEG mice demonstrated that a vast majority of insulin-positive cells coexpressed GFP, which suggests that recombination was occurring in most $\beta$ cells (Figure 5 , $\mathrm{A}$ and $\mathrm{B})$. However, we detected small numbers of insulin-expressing cells that were GFP negative (Figure 5B), which indicates lack of recombination and that the RIPCre promoter was not active in all $\beta$ cells. It would be predicted that Irs 2 would not be deleted in these cells and therefore they are involved in the preservation or recovery of $\beta$ cell mass. Indeed, analysis of 9-month-old RIPCreIrs 2 KOZEG mice demonstrated that in many islets, a significant proportion of the insulin-positive $\beta$ cells no longer expressed GFP (Figure 5, $\mathrm{C}$ and D). Comparison of the numbers of GFP-positive $\beta$ cells in 9-month-old mice demonstrated that GFP expression loss occurred significantly more often in RIPCreIrs2KOZEG than control mice (percentage of GFP-negative $\beta$ cells: RIPCreIrs 2 KOZEG, $50.9 \% \pm 1.2 \%$ vs. RIPCreZEG, $10.1 \% \pm 1.1 \% ; P<0.001 ; 2,062 \beta$ cells sampled in 54 islets from 4 RIPCreIrs 2 KOZEG mice and 2,987 $\beta$ cells sampled in 45 islets from 3 RIPCreZEG mice).

To further characterize the mechanism of $\beta$ cell recovery, we used a duct-specific lectin (Dolichos biflorus agglutinin [DBA]) to identify duct epithelial cells (20). GFP or insulin expression was not detected in DBA-positive duct structures in RIPCreIrs2KOZEG mice at 9 months of age (Figure 5, E-G). Likewise, in 9-monthold RIPCreIrs 2 KOZEG mice, in 296 islets sampled from 4 mice, no 

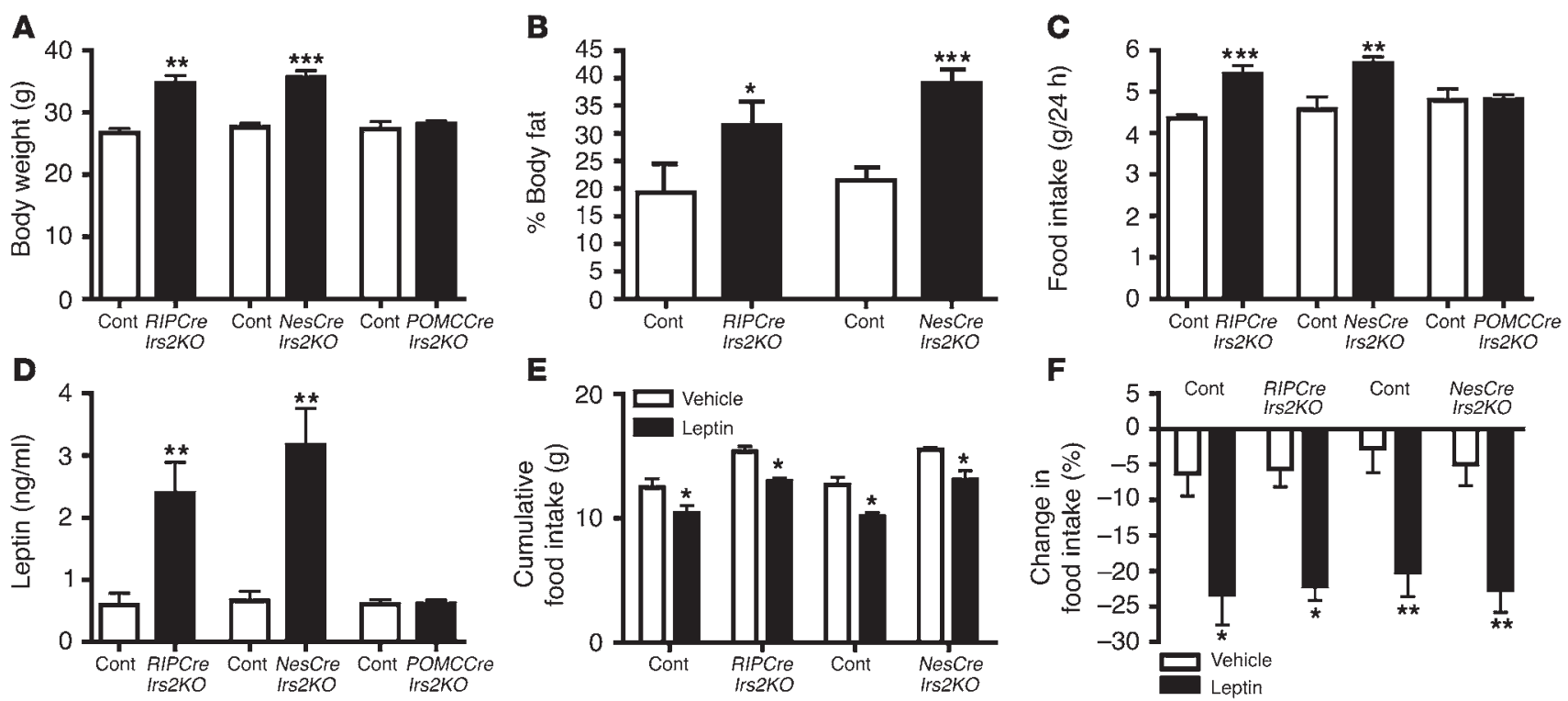

E
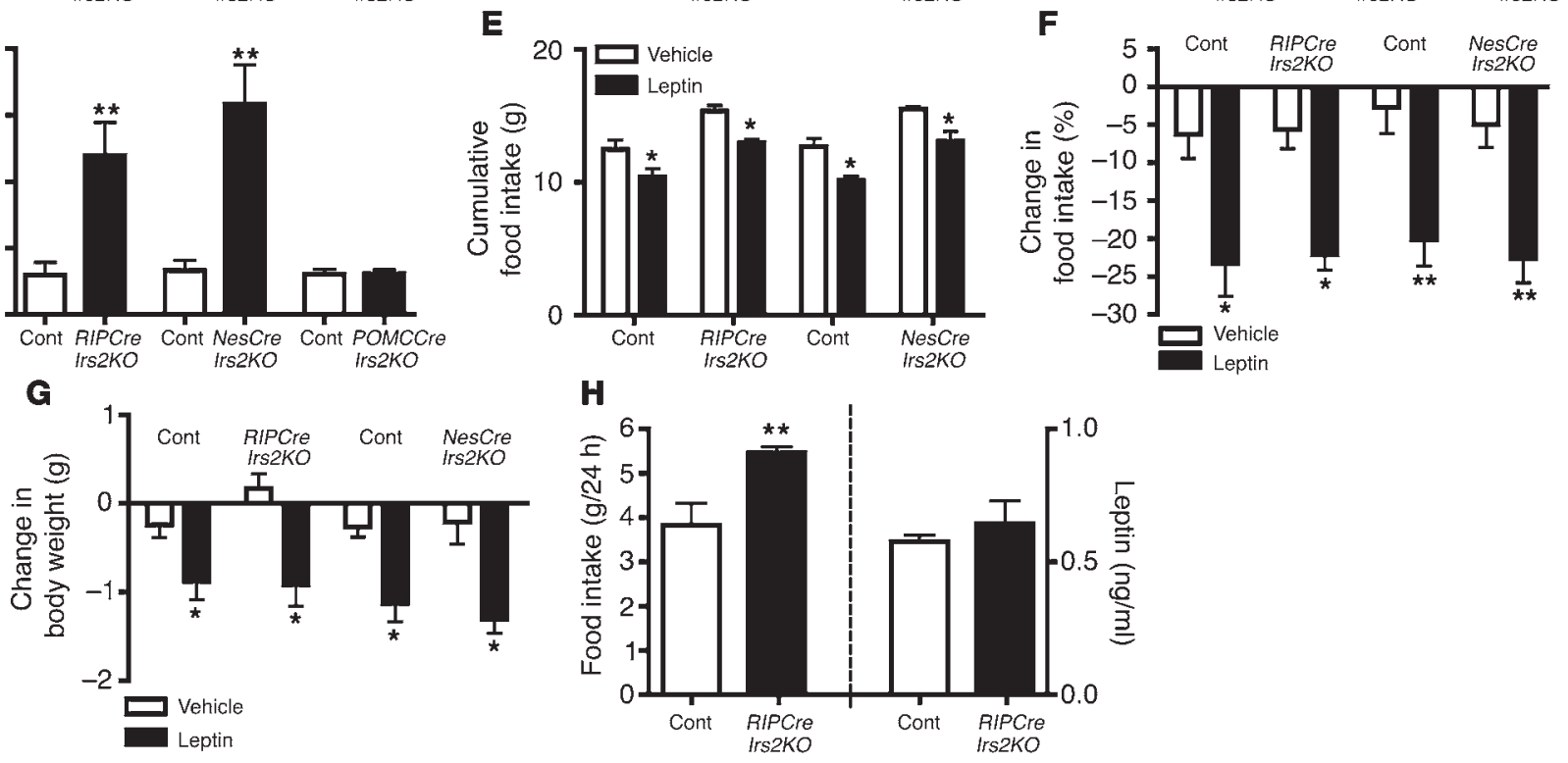

Figure 4

Hypothalamic function in RIPCrelrs2KO, NesCrelrs2KO, and POMCCrelrs2KO mice. (A) Body weight was measured in 12-week-old male mice of the indicated genotypes. (B) Total body fat was determined by MRI in 16-week-old male mice of the indicated genotypes. (C) Cumulative 24-hour food intake was measured in 12-week-old male mice of the indicated genotypes. (D) Fasting blood leptin levels of 12-week-old male mice of the indicated genotypes were measured after a 16-hour overnight fast. (E-G) Cumulative food intake, percent reduction in food intake compared with baseline, and reduction in bodyweight were measured over a 3-day period of treatment with leptin (5 mg/kg) or vehicle in 6-8-weekold male mice of the indicated genotypes. (H) Food intake and fasting leptin levels were determined in 5-week-old male mice of the indicated genotypes. Data in $\mathbf{A}-\mathbf{H}$ data represent the mean \pm SEM for $8-10$ animals of each genotype. ${ }^{*} P<0.05,{ }^{* *} P<0.01$, and ${ }^{* *} P<0.001$.

DBA-positive cells were found within islets (Figure 5, E-G). These findings suggest that duct cells that have differentiated to insulin-producing cells within ducts or duct cells that migrate to islet structures before converting to $\beta$ cells do not make a significant contribution to the $\beta$ cell repopulation. These findings do not exclude the possibility that ductal precursor cells that express neither duct markers nor insulin are involved in this process.

Characterization of RIPCre neurons and comparison with POMC neurons. Our studies demonstrate that RIPCre neurons play a role in energy homeostasis and growth and that deletion of Irs 2 in these cells generates a phenotype with similarities to that of melanocortin pathway mutants. However, our genetic evidence suggests that deletion of Irs2 in POMC neurons does not account for the hypothalamic phenotype seen in RIPCreIrs $2 \mathrm{KO}$ or NesCreIrs $2 \mathrm{KO}$ mice. RT-PCR analysis of expression of hypothalamic feeding peptides in RIPCreIrs $2 K O$ and NesCreIrs $2 \mathrm{KO}$ mice demonstrated reduced POMC expression (POMC mRNA: $42 \%$ reduction in NesCreIrs $2 \mathrm{KO}$ mice normalized to control mice, $P<0.05, n=5 ; 48 \%$ reduction in RIPCreIrs $2 \mathrm{KO}$ mice normalized to control mice, $P<0.05, n=8$ ) but normal neuropeptide $\mathrm{Y}(\mathrm{NPY})$ and agouti-related protein (AgRP) expression (data not shown), which suggests an effect on melanocortin circuits. No alteration in hypothalamic POMC, AgRP, and NPY expression was seen in POMCCreIrs $2 \mathrm{KO}$ mice. Therefore, to characterize the relationship between RIPCre neurons and melanocortin pathways, we performed ISH/ICC analysis and electrophysiological studies of RIPCre and POMCCre neurons. POMC- and GFP-expressing neurons in the hypothalamus were clearly identified by ISH and ICC, respectively, in the same slices (Figure 6, $\mathrm{A}$ and $\mathrm{B}$ ), and no GFP-positive neurons colocalized with POMC mRNA. POMC and RIPCre neurons, however, are closely associated with each other. Similarly, no coexpression of GFP was demonstrated in NPY neurons, but close apposition of these neuronal populations was observed (Figure 6, C and D). Combined ICC for $\alpha$ melanocyte-stimulating hormone $(\alpha \mathrm{MSH})$ and GFP demonstrated no coexpression, but many GFP neurons were in close proximity to $\alpha \mathrm{MSH}$-positive fibers, which suggests that they may be targets for POMC neurons (Figure 6E).

Whole-cell current-clamp recordings were made from GFP-positive hypothalamic arcuate neurons from RIPCreZEG mice. Under control recording conditions, RIPCre neurons spontaneously fired action potentials and had a mean resting potential of $-50 \pm 1 \mathrm{mV}$ 

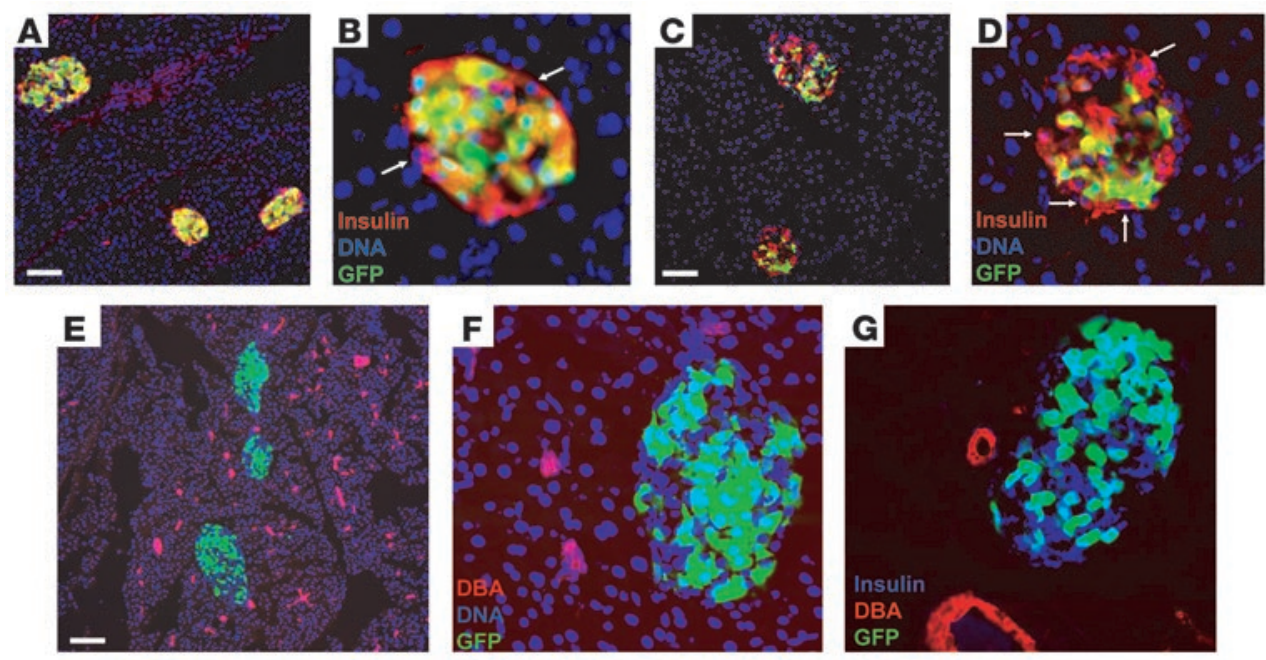

Figure 5

Analysis of recombination and duct-marker expression in islets from RIPCrelrs2KOZEG mice. (A-D) Immunofluorescence staining for insulin (red) in islets from 4-week-old ( $\mathbf{A}$ and $\mathbf{B}$ ) and 9-month-old (C and $\mathbf{D})$ RIPCrelrs2KOZEG mice stained for DNA (DAPI, blue). White arrows indicate $\beta$ cells that do not express GFP and have not undergone recombination. Many cells in the 9-month-old islet do not express GFP. (E-G) Labeling of ducts with DBA in islets from 9-month-old RIPCrelrs2KOZEG mice stained blue for either DNA $(\mathbf{E}$ and $\mathbf{F}$ ) or insulin (G). No duct marker is expressed in GFP-negative $\beta$ cells. Scale bars: $100 \mu \mathrm{m}$.

$(n=9 / 11)$ neurons (Figure 7, Iand J). The effect of insulin, MTII, and leptin on neuronal activity was extremely slow to reverse and was, in many cases, irreversible over the time course of the experiments. These experiments suggest that RIPCre neurons are a population distinct from either POMC or NPY neurons but lie within a melanocortinand insulin-regulated neuronal mechanism.

\section{Discussion}

Through global gene deletion, we and others have previously implicated Irs 2 in the regulation of $\beta$ cell function and peripheral glucose metabolism and the central regulation of energy homeostasis $(10,11,19,22)$. These studies have suggested but not proved that Irs 2 mediates both $\beta$ cell growth and leptin and insulin action in the

and input resistance of $1,862 \pm 197 \mathrm{M} \Omega(n=62)$. Bath application of the $\alpha \mathrm{MSH}$ analog melanotan II (MTII) (a nonselective melanocortin $3 / 4$ receptor agonist) at $100 \mathrm{nM}$ caused long-lasting depolarization in the majority of cells tested (from $-53 \pm 3 \mathrm{mV}$ to $-48 \pm 2 \mathrm{mV} ; P<0.01 ; n=9 / 13)$, associated with increased spike firing (Figure 6, F and $\mathrm{G}$ ).

To demonstrate the MTII excitatory effect more clearly, we applied a small hyperpolarizing current to individual neurons, such that action potential frequency was markedly reduced. Under these conditions, MTII (100 nM) caused depolarization and increased firing frequency (Figure 6H). Furthermore, the application of MTII (100 nM) to RIPCre neurons, following incubation of the slice with tetrodotoxin (TTX; $500 \mathrm{nM}$ ) to block spike firing and prevent synaptic transmission, caused significant depolarization $(n=4)$, which indicates a direct action (Figure 6I). To further characterize RIPCre neurons and differentiate them from POMC (and NPY) neurons, we determined the actions of insulin and leptin on the electrical properties of RIPCre and POMC neurons. Leptin has been demonstrated to depolarize POMC neurons (21), and our current results support this finding. Pressure ejection of leptin $(50 \mathrm{nM})$ for 60 seconds directly above the recorded neuron caused an increase in spike frequency and a small depolarization (from $-47 \pm 2 \mathrm{mV}$ to $-44 \pm 3 \mathrm{mV} ; P<0.04$ ) of a minority population of POMC neurons $(n=5 / 13)$ (Figure $7, \mathrm{~A}-\mathrm{C})$. In contrast, leptin $(50 \mathrm{nM})$ did not affect action potential frequency or resting membrane potential ( $-46 \pm 3 \mathrm{mV}$ vs. $-47 \pm 3 \mathrm{mV} ; n=10$; Figure 7 , D and $\mathrm{E}$ ) in RIPCre neurons. Pressure ejection of insulin (10 nM) for $60 \mathrm{sec}-$ onds produced a significant increase in action potential frequency, concomitant with cell depolarization (from $-49 \pm 4$ to $-40 \pm 4 \mathrm{mV}$; $P<0.01)$ in the majority of recordings $(n=6 / 9)$ from RIPCre neurons (Figure $7, \mathrm{~F}-\mathrm{H}$ ). In contrast, pressure injection of insulin $(10 \mathrm{nM})$ onto POMC neurons resulted in hyperpolarization (from $-48 \pm 1 \mathrm{mV}$ to $-55 \pm 2 \mathrm{mV}$; $P<0.001)$ and reduced action potential frequency in most
CNS. To elucidate the contribution of Irs2 to this complex phenotype in specific tissues, we generated mice with a conditional allele of Irs 2 to permit deletion in a number of cell types. We initially used RIPCre transgenic mice to generate RIPCreIrs $2 \mathrm{KO}$ mice lacking Irs 2 in $\beta$ cells and a population of hypothalamic neurons, and indeed it has recently been reported that RIPCreIrs $2 K O$ mice display phenotypes due to this mixed pattern of deletion $(13,14)$. These mice developed reduced $\beta$ cell mass, obesity, somatic overgrowth, hyperinsulinemia, and hyperleptinemia but did not progress to an overt diabetic phenotype because of an unexplained recovery in $\beta$ cell mass. However, because of the inability to dissociate $\beta$ cell and hypothalamic phenotypes, a number of questions regarding the role of Irs2 remain unanswered (15). To directly address such issues that we encountered with our own RIPCreIrs $2 \mathrm{KO}$ mice, we also generated NesCreIrs $2 \mathrm{KO}$ mice, lacking Irs 2 in all neurons but not the endocrine pancreas, and POMCCreIrs $2 K O$ mice, lacking Irs 2 in hypothalamic POMC neurons, which have been implicated in mediating leptin's effects on energy homeostasis (23).

Consistent with recent reports $(13,14), 12$-week-old RIPCreIrs $2 K O$ mice had reduced $\beta$ cell mass and displayed mildly elevated fasting blood glucose levels, impaired glucose tolerance, and hyperinsulinemia. They developed a marked hypothalamic phenotype resembling that of mice with defects in melanocortin action. In contrast, NesCreIrs $2 \mathrm{KO}$ mice, which have normal $\beta$ cell Irs 2 expression, had increased $\beta$ cell mass in response to insulin resistance and displayed the obesity and overgrowth syndrome. These findings demonstrate that $\beta$ cell mass reduction is due to Irs 2 deletion solely in $\beta$ cells and not in the CNS. However, NesCreIrs $2 \mathrm{KO}$ did develop elevated fasting blood glucose levels and hyperinsulinemia, which suggests that neuronal Irs2 pathways are required for normal glucose homeostasis but that the increase in $\beta$ cell mass seen in NesCreIrs $2 \mathrm{KO}$ mice could compensate for insulin resistance. 


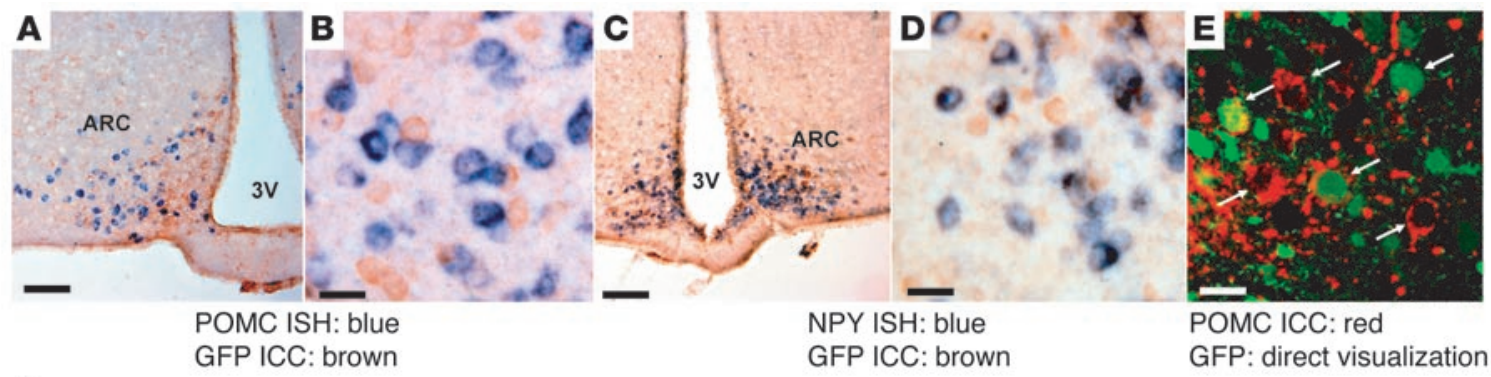

$\mathbf{F}$
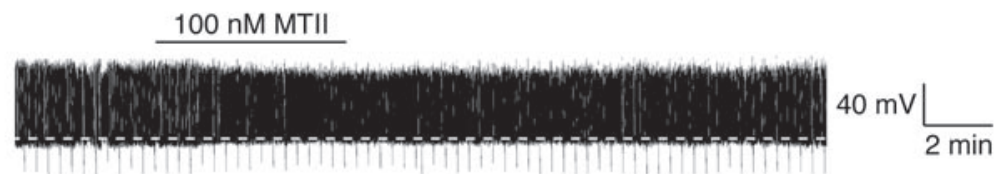

G

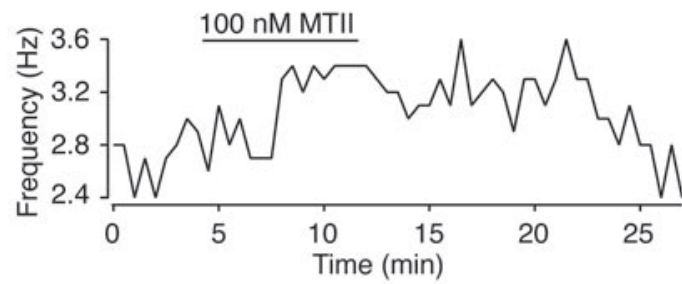

H

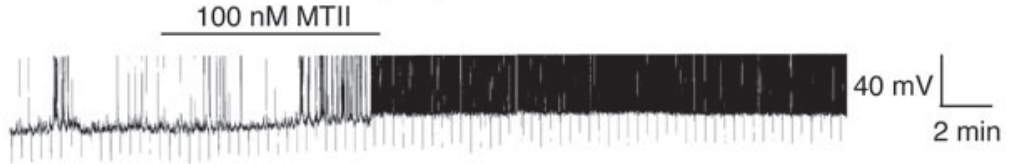

I

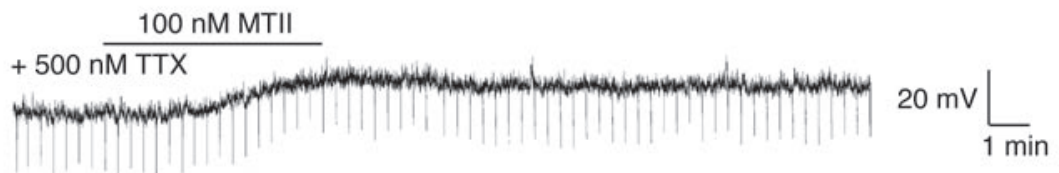

\section{Figure 6}

Characterization of RIPCre neurons by ICC, ISH, and electrophysiological analysis. (A and B) Dual ISH for POMC and ICC for GFP was performed on hypothalamic sections from RIPCreZEG mice. Representative low- (A) and high-power (B) views are shown. (C and D) Dual ISH for NPY and ICC for GFP was performed on hypothalamic sections from RIPCreZEG mice. Representative low- (C) and high-power (D) views are shown. ARC, arcuate nucleus. (E) Fluorescence ICC for POMC was performed on hypothalamic sections from RIPCreZEG mice. Neurons expressing POMC are red and those expressing GFP are green. Arrows indicate noncolocalized neurons and GFP neurons that are abutted by POMC fibers. A representative confocal image is shown. Scale bars: $50 \mu \mathrm{m}(\mathbf{A}$ and $\mathbf{C})$ and $10 \mu \mathrm{m}$ (B, D, and E). (F-I) Current-clamp recordings were made from RIPCreZEG neurons in the absence and presence of the mixed melanocortin 3/4 receptor agonist MTII, as indicated above the traces. (F) Representative recording demonstrating MTII depolarization, resulting in a small increase in spike frequency $(\mathbf{G})$. This depolarization is more clearly represented in neurons that have sub-spike thresholds, achieved by application of a constant hyperpolarizing current $(\mathbf{H})$. MTII also depolarizes neurons in the presence of TTX (I), indicative of a direct action. The action potentials in panel $\mathbf{H}$ have been truncated to show clearly the depolarizing effect of MTII. Note that the MTII depolarization was irreversible over the time course of the recordings in cells represented in $\mathbf{H}$ and $\mathbf{I}$.

In contrast to Lin et al. (13), we found that in 9-month-old RIPCreIrs $2 K O$ mice, there was a persistent reduction in $\beta$ cell mass compared with that of control mice, although the mass was increased compared with that of 3-month-old RIPCreIrs $2 \mathrm{KO}$ mice. At later ages, therefore, RIPCreIrs $2 \mathrm{KO}$ mice had glucose intolerance but did not display marked fasting hyperglycemia and never developed the marked progressive diabetic phenotype of the global Irs2null mouse. Anatomical studies of recombination using a GFP indicator mouse in either a wild-type or Irs 2 flox background revealed that as early as 4 weeks, small numbers of $\beta$ cells did not harbor the recombination event. By 9 months of age, significant numbers of $\beta$ cells in RIPCreIrs $2 K O$ mice not expressing GFP had repopulated the islets, but many GFP-positive cells undergoing recombination were still present, which explains the persistent reduction in $\beta$ cell mass. Our studies demonstrate that the reduction in recombina- tion occurs predominantly in RIPCreIrs 2 KOZEG as opposed to RIPCreZEG islets, which suggests that Irs 2 signaling itself is required for expression of the RIPCre transgene. Indeed, insulin gene expression appears to require an intact insulin signaling pathway in the $\beta$ cell $(2,24,25)$. With Irs2 largely absent within $\beta$ cells, under conditions of insulin resistance there may be potential selection for preexisting $\beta$ cells not expressing the RIPCre transgene and therefore not undergoing deletion of Irs 2 to expand and repopulate the islet. In 9-month-old mice, we did not detect GFP expression and Cremediated recombination in pancreatic ducts, and so potentially the GFP-negative $\beta$ cells could have arisen from duct cells. However, we could not detect expression of a duct cell marker within islets of 9-month-old RIPCreIrs $2 \mathrm{KO}$ mice nor could we find insulin expression in ducts. The absence of deletion in ducts also suggests that the $\beta$ cell phenotype in RIPCreIrs $2 \mathrm{KO}$ mice results from loss of 
A

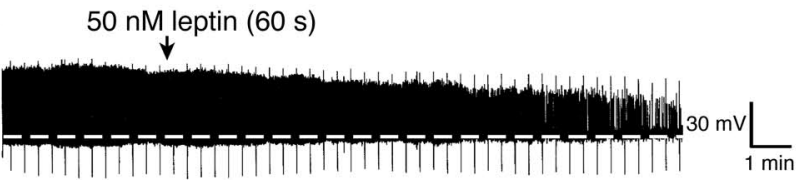

B $50 \mathrm{nM}$ leptin (60 s)

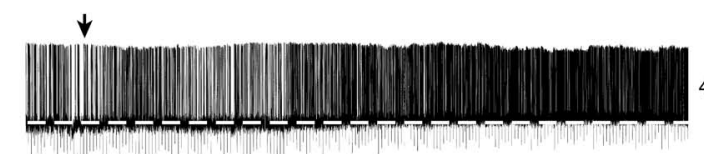

$40 \mathrm{mV} \underset{4 \mathrm{~min}}{\longleftarrow}$

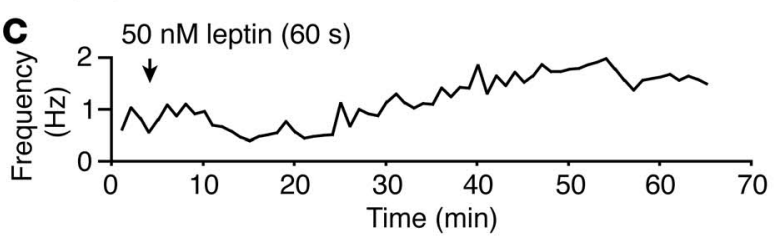

D $50 \mathrm{nM}$ leptin (60 s)
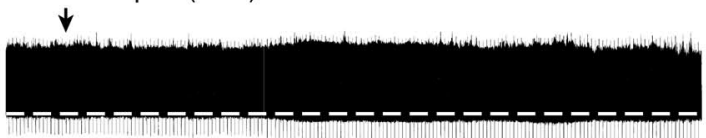

E $\quad 50 \mathrm{nM}$ leptin (60 s)

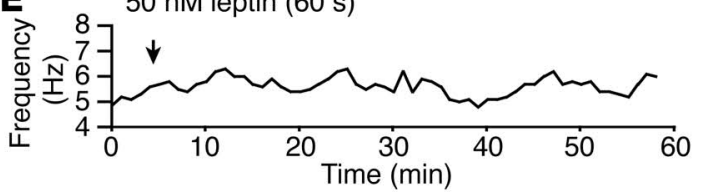

$\mathbf{F}$
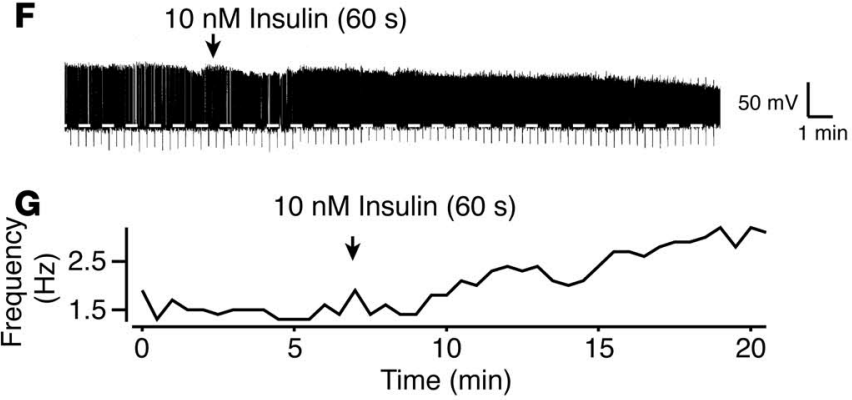

H

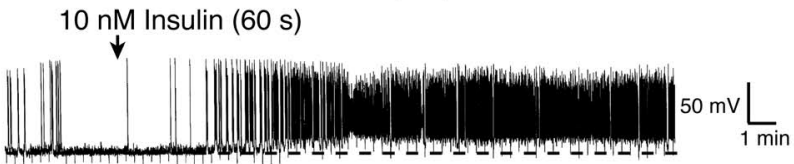

I $10 \mathrm{nM}$ Insulin (60 s)
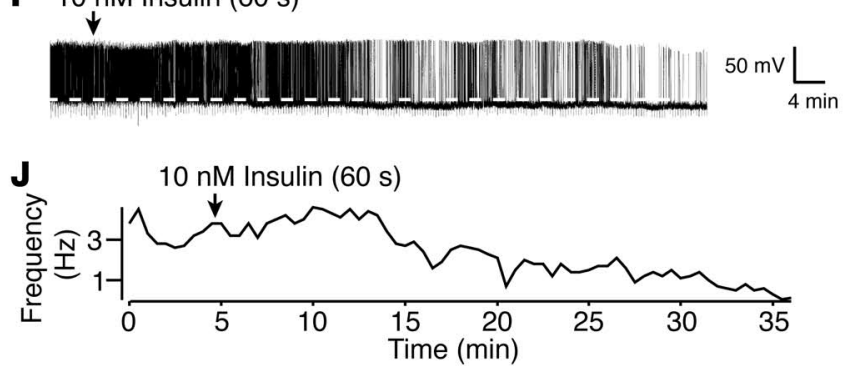

Figure 7

Electrophysiological characteristics of RIPCre and POMC neurons in response to insulin and leptin. (A) Representative recordings from individual arcuate neurons are shown for POMCCreZEG (A-C, I, and J) and RIPCreZEG (D-H). Leptin (50 nM) and insulin (10 nM) were pressure-ejected (2-5 psi) for 60 seconds (as denoted by arrows). (A) Leptin depolarizes the POMCCreZEG neuron, and this is associated with significant attenuation of spike amplitude. The recording from the neuron shown in B was hyperpolarized to subthreshold potentials by injection of constant current $(2-5 \mathrm{pA})$ through the recording electrode. Application of leptin depolarized and increased the firing rate of the neuron. (C) Diary plot of spike frequency for the neuron shown in B. In contrast, leptin had no effect on membrane potential (D) and spike frequency (E) in RIPCreZEG neurons. Insulin caused depolarization of the RIPCreZEG neuron (F) and increased spike frequency $(\mathbf{G})$, with spike attenuation. As shown in $\mathbf{H}$, the neuron was hyperpolarized to subthreshold potentials as above, and application of insulin clearly depolarizes this neuron with a large increase in spike frequency. In contrast, insulin caused hyperpolarization of POMCCreZEG neurons (I), which was accompanied by a reduction in firing rate ( $\mathbf{J}$ ).

Irs2 in mature insulin-producing cells rather than any precursor or stem cell population. Taken together, these findings provide anatomical evidence that a small number of preexisting $\beta$ cells that escape Irs 2 deletion at an early stage in RIPCreIrs $2 \mathrm{KO}$ mice repopulate the islets. Our studies cannot categorically exclude the possibility that duct-derived precursors expressing neither insulin nor duct markers contribute to the repopulation process. However, recent lineage tracing studies (20) suggest that proliferation of mature $\beta$ cells is the major mechanism for $\beta$ cell expansion in adult mice. Our findings suggest that persistent Irs 2 expression in mature $\beta$ cells is required for the compensatory response to insulin resistance.

The preservation of $\beta$ cell mass in NesCreIrs $2 \mathrm{KO}$ mice dissociates hypothalamic dysfunction from reduced $\beta$ cell mass. It has been suggested that nestin expression is a characteristic of pancreatic islet stem cells $(26,27)$, but recently lineage tracing studies, utilizing the same NesCre mouse used in our studies, demonstrated that pancreatic exocrine, ductal, and endothelial cells but not islet endocrine cells express nestin $(18,28)$. The finding of increased islet mass in NesCreIrs $2 \mathrm{KO}$ mice further supports the concept that nestin-positive cells do not contribute to the endocrine pancreas, as deletion of Irs 2 in these cells would have been anticipated to reduce $\beta$ cell mass.
The hypothalamic phenotypes seen in RIPCreIrs $2 K O$ and NesCreIrs $2 K O$ mice suggested defects in melanocortin function, and in RIPCreIrs $2 \mathrm{KO}$ and NesCreIrs $2 \mathrm{KO}$ mice, we detected reduced hypothalamic POMC expression. Deletion of the leptin receptor in POMC neurons generates mice that have some phenotypic features in common with RIPCreIrs $2 \mathrm{KO}$ mice, including obesity (23). It has been suggested that RIPCre neurons are POMC neurons and that Irs2 signaling events are required for central leptin action $(14,29)$. Our results, however, do not confirm these findings and provide evidence to define the role and sites of Irs2 pathways in the CNS. We demonstrate that deletion of Irs2 in POMC neurons did not recapitulate the hypothalamic phenotype and that RIPCre neurons do not express POMC or NPY. Furthermore, RIPCreIRS2KO and NesCreIRSKO mice were sensitive to peripherally administered leptin at 6 weeks of age. Five-week-old RIPCreIRS2KO and NesCreIRSKO mice are hyperphagic but not hyperleptinemic, which suggests that elevated leptin levels seen at later ages result from greater adiposity due to increased energy intake rather than primary central leptin resistance. This is consistent with the observation that central leptin administration to Irs2-null mice causes reduction in fat mass (12). Young nonobese hyperphagic melanocortin 4 receptor-null mice, which resemble RIPCreIRS2KO and NesCreIRSKO mice, are sensitive 
to the anorexigenic effects of leptin but develop leptin resistance as they become obese (30). In preliminary observations, mice lacking Irs 2 in AgRP neurons, generated using an AgRPCre transgenic mouse (31), also do not develop a marked hypothalamic phenotype (H. Al-Qassab et al., unpublished observations). Therefore, these studies implicate Irs2 signaling in neurons distinct from POMC and AgRP/NPY populations in the regulation of energy homeostasis and growth and suggest that Irs2 is not an obligatory component of CNS leptin signaling pathways.

Electrophysiological analysis showed that RIPCre neurons depolarized in response to insulin and MTII, which suggests that they could be mediating the effects of insulin in the CNS in a melanocortin-sensitive neuronal pathway. Furthermore, we found no electrophysiological effect of leptin upon arcuate RIPCre neurons, which suggests that this is not a leptin-sensitive neuronal population and therefore may explain why RIPCreIRS2KO mice are not leptin resistant. In contrast, leptin depolarized and insulin hyperpolarized POMC neurons. These opposite effects upon neuronal activity perhaps explain the lack of phenotype in POMCCreIrs $2 \mathrm{KO}$ mice and distinguish RIPCre neurons electrophysiologically from both POMC and NPY neurons $(21,32)$. It remains possible that the RIPCre neurons in other hypothalamic regions such as the VMH may be mediating the effects of leptin, and we have started to examine this possibility using additional mouse mutants. However, our observation of leptin sensitivity in the NesCreIrs $2 \mathrm{KO}$ mice suggests that CNS Irs2 is not required for leptin action.

Our studies have demonstrated that CNS Irs2 pathways acting in a neuronal population distinct from POMC and NPY neurons regulate energy homeostasis and growth. Arcuate RIPCre neurons are targets for insulin and melanocortin but not leptin action, but it remains to be determined what neuropeptides and transmitters are expressed in this population. Irs 2 in $\beta$ cells is required for the maintenance of $\beta$ cell mass, but $\beta$ cells that escape Cre-mediated recombination are able to repopulate islets with time. Our observations clarify the role of Irs 2 in $\beta$ cell function and energy homeostasis and suggest that modulation of Irs2 function may be of use in the treatment of diabetes and obesity.

\section{Methods}

Generation of floxed allele of Irs 2 and genotyping strategies for Irs2lox and Cre and ZEG transgenic mice. The murine Irs2 gene was cloned from a 129Sv mouse genomic PAC library. We cloned $2.8 \mathrm{~kb}$ of $5^{\prime}$ homology from the Irs 2 locus upstream of a floxed neomycin cassette using appropriate linkers. The Irs 2 coding region was subcloned with linkers, introducing a loxP site $3^{\prime}$ to the Irs 2 coding region. A $3-\mathrm{kb}$ fragment of $3^{\prime}$ region of the Irs 2 locus was cloned downstream of this loxP site using linkers to generate the final construct (Figure 1A). 129Sv/EvTac1 ES cells were transfected with Pac1-linearized targeting construct by electroporation. Cells were subjected to selection with G418 and ganciclovir; surviving clones were expanded and genomic DNA extracted and subjected to analysis by PCR and Southern blotting to detect homologous recombination (Figure 1, B-D). Targeted clones were subsequently transfected with Cre recombinase plasmid to remove the neomycin cassette and screened by Southern blotting and PCR (Figure 1, $\mathrm{C}$ and D). ES cells were injected into blastocysts derived from C57BL/6J mice, which were implanted into pseudopregnant $\mathrm{CD}-1$ foster mothers. Chimeric male mice were bred with C57BL/6J mice and germ-line transmission confirmed by PCR and Southern blot analysis. Irs $2 l o x$ mice were intercrossed with C57BL/6J RIPCre and C57BL/6J NesCre mice obtained from the Jackson Laboratory $(33,34)$ to generate compound heterozygous mice. Doubleheterozygous mice were crossed with Irs2lox mice to obtain WT, Irs2lox/lox, Cre, and CreIrs2lox/lox mice. Mice lacking Irs2 in RIPCre-expressing cells were designated RIPCreIrs $2 \mathrm{KO}$ and in nestin Cre-expressing cells NesCreIrs2KO. POMCCre mice were generated using a BAC transgenic approach (35). POMCCre mice were intercrossed with Irs2lox mice and bred as described above to obtain POMCCreIrs $2 K O$ mice. ZEG mice, which carry a Cre-activated GFP transgene (16), or Rosa26lacZ indicator mice (17) were intercrossed with the RIPCre and POMCCre mice and Irs2lox mice to obtain mice that express GFP or lacZ in RIPCre- or POMCCre-expressing cells as well as mice that also lack Irs 2 and express the indicator gene. Mice were maintained on a 12-hour light/dark cycle with free access to water and standard mouse chow (4\% fat, RM1; Special Diet Services) and housed in specific pathogen-free barrier facilities. Mice were handled and all in vivo studies performed with approval by the Home Office (London, United Kingdom). All knockout and transgenic mice were studied with appropriate littermate controls. Wild-type, Cre transgenic and Irs2lox/lox mice were phenotypically indistinguishable, and equal numbers of the mice of these genotypes were used as controls. Genotyping of the mice was performed by PCR amplification of tail DNA. For Irs2lox genotyping, we used primers that flank the $3^{\prime}$ loxP site (Figure 1E): loxP forward, 5'-ACTTGAAGGAAGCCACAGTCG-3' and loxP reverse, $5^{\prime}$-AGTCCACTTTCCTGACAAGC- ${ }^{\prime}$. Cre recombinase, Rosa26lacZ, and $Z E G$ genotyping was performed as previously described $(16,17)$. For detection of Cre-mediated excision of Irs 2 , genomic DNA was isolated from pancreatic islets, hypothalami, and other tissues by heating in $50 \mathrm{mM} \mathrm{NaOH}$ at $100^{\circ} \mathrm{C}$ for 10 minutes. Primers located $1.1 \mathrm{~kb}$ upstream of the $5^{\prime}$ loxP site ( $5^{\prime}$-GGGAACCTGACAAGTGAATG-3') and $0.2 \mathrm{~kb}$ downstream of the $3^{\prime}$ loxP site (loxP 5'-AGTCCACTTTCCTGACAAGC-3') amplified a $1.3-\mathrm{kb}$ product if recombination had occurred.

Immunoprecipitation and Western blotting. Tissues were removed and homogenized in lysis buffer, solubilized for 30 minutes on ice, and clarified by centrifugation. Supernatants were immunoprecipitated for 2 hours with an anti-Irs2 antibody as described (10). Immune complexes were collected with $100 \mu \mathrm{l}$ of $50 \%$ slurry of protein A-sepharose, washed with lysis buffer, resolved on 7.5\% SDS-PAGE, and transferred to nitrocellulose. The blots were probed with polyclonal antibody against Irs2 and enhanced chemiluminescence (Amersham Biosciences) detection.

Metabolic studies. Body weights were determined using a Sartorius BP610 balance. Nose to anus length was measured either postmortem or in anesthetized mice, with the observer blinded to genotype. Blood samples were collected from mice via tail vein bleeds or from cardiac puncture performed on terminally anesthetized mice. Blood glucose was measured using a Glucometer Elite (Bayer Corp.). We determined plasma insulin levels using an ultrasensitive rat insulin ELISA (Crystalchem Inc.) using a mouse standard and leptin levels using a mouse leptin ELISA (Crystalchem Inc.). Glucose tolerance tests were performed on mice after a 16 -hour overnight fast. Animals were injected intraperitoneally with D-glucose $(1.5 \mathrm{~g} / \mathrm{kg})$ and blood glucose levels determined at the time points indicated in Figure 3, B and C.

Food intake and leptin and treatment studies. Mice were singly housed and allowed to acclimatize for a week prior to study. Food intake and body weight were measured for 3 consecutive days at the ages indicated in the Figure 4 legend. As necessary, we acclimatized mice by subjecting them to overnight fasts and sham injections prior to the study protocol. For peripheral leptin treatment, mice were treated with either $5 \mathrm{mg} / \mathrm{kg}$ recombinant mouse leptin (R\&D Systems) or vehicle injected i.p. 1 hour before lights out for 3 consecutive days. Food and body weights were recorded before injection, during the treatment period, and for a 3-day wash-out period following the study.

ICC and ISH. Brains were harvested following transcardiac perfusion with RNAse-free PBS and 4\% paraformaldehyde, postfixed in $4 \%$ paraformaldehyde, and transferred to RNAse-free $30 \%$ sucrose prior to freezing. Thirty-micrometer floating sections were cut using a sliding microtome. Twenty-micrometer cryostat sections were thaw-mounted on polylysine-coated microscope slides. Floating sections were washed 
in potassium PBS (KPBS), $\mathrm{pH} 7.4$, blocked with $2 \%$ serum in $\mathrm{KPBS} / 0.4 \%$ Triton X-100 (KPBS-T) for 1 hour at room temperature, and then incubated with primary antibodies in KPBS-T for 48 hours at $4{ }^{\circ} \mathrm{C}$. Slices were incubated with appropriate secondary antibodies for 1 hour in KPBS-T before being washed in KPBS. For chromogenic detection, slices were incubated for 60 minutes in avidin-DH/biotinylated HRP (ABC Elite; Vector Laboratories) in KPBS-T and washed in KPBS, then in $150 \mathrm{mM}$ sodium acetate, and nickel-enhanced detection was performed with a 3,3'diaminobenzidine substrate kit for peroxidase (Vector Laboratories). For some anti- $\alpha \mathrm{MSH}$ staining experiments, mice were treated with intracerebroventricular colchicine ( $2 \mu \mathrm{l}$ of $20 \mathrm{mg} / \mathrm{ml}$ solution in $0.9 \%$ saline infused over 10 minutes into the lateral ventricle) 24 hours prior to perfusion fixation and biotinylated tyramide amplification and fluorescent detection with streptavidin-conjugated Alexa Fluor 594 (Invitrogen Corp.) were used. Slices were mounted on polylysine-coated microscope slides and coverslipped with buffered glycerol. Primary antibodies used were rabbit anti-Irs2 antibody (United Biomedical Inc.), sheep anti-NPY (Chemicon International), sheep anti- $\alpha \mathrm{MSH}$ (Chemicon International), mouse monoclonal anti-GFP (Chemicon International), and mouse monoclonal anti-lacZ (Promega). For combined ISH and ICC, ISH was performed first under RNAse-free conditions. In brief, sections on slides were fixed in formaldehyde solution for 20 minutes on ice, washed twice in PBS for 5 minutes, and acetylated at room temperature for 10 minutes in $0.1 \mathrm{M}$ triethanolamine ( $\mathrm{pH}$ 8.0) with acetic acid anhydride. After washing, sections were dehydrated and air dried for 30 minutes. Hybridization buffer containing $2 \mathrm{ng} / \mu \mathrm{l}$ digoxigenin-labeled (DIG-labeled) probe was applied and sections covered with glass coverslips and hybridized overnight at $60^{\circ} \mathrm{C}$. Sections were placed in $4 \times$ SSC to remove coverslips, RNase A treated for 30 minutes at $37^{\circ} \mathrm{C}$, and washed in $2 \times \mathrm{SSC}$ at $6^{\circ} \mathrm{C}$ for 10 minutes, $1 \times$ SSC at $6^{\circ} \mathrm{C}$ for 10 minutes, $0.5 \times$ SSC at $60^{\circ} \mathrm{C}$ twice for 10 minutes, and $0.1 \times \mathrm{SSC}$ at $60^{\circ} \mathrm{C}$ for 30 minutes. Sections were cooled to room temperature in $0.1 \times$ SSC, and we used alkaline phosphatase-conjugated anti-DIG antibody to detect bound DIG-labeled probe (Roche Diagnostics Ltd.) as described above. We generated ISH riboprobes using mouse sequences (POMC, GenBank accession number NM_008895; NPY, GenBank accession number NM_023456). Imaging was performed with an Olympus BX51 microscope with either a Hamamatsu 95 black-and-white camera or a Jenoptik ProgRes C14 color camera combined with SimplePCI capture and deconvolution software (version 5.2.1, Compix Inc.). Confocal microscopy was performed on a Bio-Rad MRC1000 microscope. Colocalization of either POMC or NPY with GFP was scored in 4 arcuate sections from each of 4 RIPCreZEG mice by 2 independent observers.

Pancreatic ICC and measurement of islet mass and number. Pancreata were removed, cleared of fat and lymph nodes, fixed in Bouins solution, embedded in paraffin, and cut into $5-\mu \mathrm{m}$ sections. For GFP detection, pancreata were harvested from paraformaldehyde-perfused mice as described above. For insulin staining, sections were incubated with blocking solution containing PBS buffer with 5\% normal chicken serum and 2\% BSA for 30 minutes, and mouse anti-insulin antibody (clone K36aC10; Sigma-Aldrich) was then applied for 2 hours at room temperature or overnight at $4^{\circ} \mathrm{C}$. The sections were then incubated with chicken anti-mouse IgG-AlexaFluor 488 conjugate (Invitrogen Corp.) for 2 hours at room temperature. Transmitted light and fluorescent images were captured as described above. For quantification of $\beta$ cell area, we analyzed 5 pancreata per genotype at each time point using 4 sections at least $150 \mu \mathrm{m}$ apart from each other. For each section, the total area occupied by insulin-positive cells was scored using SimplePCI software. Results are expressed as the percentage of the total pancreatic area. Pancreatic ducts were labeled with biotinylated DBA lectin (Vector Laboratories), detection performed with fluorescently labeled streptavidin 610 (Invitrogen Corp.), and DAPI used to identify nuclei.
Islet isolation. Mice were sacrificed, the common bile duct cannulated, and its duodenal end occluded by clamping. Two milliliters of collagenase $\mathrm{V}$ solution $(1 \mathrm{mg} / \mathrm{ml}$ in HBSS $)$ was injected into the duct to distend the pancreas. The pancreas was excised, incubated at $37^{\circ} \mathrm{C}$ for 15 minutes, and mechanically disrupted in $10 \mathrm{ml}$ of HBSS. Cellular components were collected by centrifugation ( $220 \mathrm{~g}$ for 1 minute) and resuspended in $10 \mathrm{ml}$ of HBSS. Islets were handpicked under a microscope and washed once in HBSS. Islets were centrifuged at $15,600 \mathrm{~g}$ for 5 minutes and stored at $-20^{\circ} \mathrm{C}$ until DNA or protein extraction.

$m R N A$ quantification by RT-PCR analysis. Hypothalami were removed from fasted mice, homogenized in Trizol reagent (Invitrogen Corp.), and $1 \mu \mathrm{g}$ RNA was reverse transcribed using Taqman reagents (Applera Ltd.). Quantitative PCR was carried out with first-strand cDNA with primers for hypothalamic feeding peptides (23), using hypoxanthine ribosyl transferase as an internal control on an ABI Prism 7900HT sequence detection system, with SYBR green reagents (Applied Biosystems Inc.), and data analyzed according to the $2^{-\triangle \Delta C T}$ method (36).

Electrophysiology. Male RIPCreZEG and POMCCreZEG mice (8-16 weeks old) were killed by cervical dislocation. Brains were rapidly transferred to a ice-cold slicing solution containing $2.5 \mathrm{mM} \mathrm{KCl}, 1.25 \mathrm{mM} \mathrm{NaH}_{2} \mathrm{PO}_{4}$, $28 \mathrm{mM} \mathrm{NaHCO}_{3}, 0.5 \mathrm{mM} \mathrm{CaCl}_{2}, 7 \mathrm{mM} \mathrm{MgCl}_{2}, 7 \mathrm{mM}$ D-glucose, $1 \mathrm{mM}$ ascorbate, $3 \mathrm{mM}$ pyruvate, and $235 \mathrm{mM}$ sucrose and equilibrated with $95 \% \mathrm{O}_{2} / 5 \% \mathrm{CO}_{2}$ to give a $\mathrm{pH}$ of 7.4 , and $350-\mu \mathrm{m}$ coronal brain slices were prepared using a Vibratome Series 1000 . Arcuate nucleus slices were kept at room temperature in a normal external solution containing $125 \mathrm{mM}$ $\mathrm{NaCl}, 2.5 \mathrm{mM} \mathrm{KCl}, 1.25 \mathrm{mM} \mathrm{NaH}_{2} \mathrm{PO}_{4}, 25 \mathrm{mM} \mathrm{NaHCO}_{3}, 2 \mathrm{mM} \mathrm{CaCl}_{2}$, $1 \mathrm{mM} \mathrm{MgCl}_{2}, 10 \mathrm{mM}$ D-glucose, $15 \mathrm{mM}$ D-mannitol, $1 \mathrm{mM}$ ascorbate, and $3 \mathrm{mM}$ pyruvate equilibrated with $95 \% \mathrm{O}_{2} / 5 \% \mathrm{CO}_{2}, \mathrm{pH}$ 7.4. For wholecell recordings, slices were continuously perfused with normal external solution (in the absence of ascorbate and pyruvate and with $\mathrm{CaCl}_{2}$ and $\mathrm{MgCl}_{2}$ concentrations adjusted to 0.5 and $2.5 \mathrm{mM}$, respectively) at a rate of $5-10 \mathrm{ml} / \mathrm{min}$. Neurons were identified using epifluorescence and differential interference contrast optics using an upright Zeiss Axioskop 2 FS plus microscope. Borosilicate patch pipettes (5-8 M $)$ were filled with an internal solution containing $130 \mathrm{mM}$ potassium gluconate, $10 \mathrm{mM} \mathrm{KCl}$, $0.5 \mathrm{mM}$ EGTA, $10 \mathrm{mM}$ HEPES, $1 \mathrm{mM} \mathrm{NaCl}, 0.28 \mathrm{mM} \mathrm{CaCl}_{2}, 3 \mathrm{mM} \mathrm{MgCl}_{2}$, $3 \mathrm{mMNaATP}, 0.3 \mathrm{mM}$ tris-GTP, $14 \mathrm{mM}$ phosphocreatine ( $\mathrm{pH}$ 7.2). Data were recorded and stored on digital audio tape, which enabled off-line analysis. We examined changes in input resistance by monitoring membrane potential responses to negative, rectangular current pulses $(5-20$ pA, $200 \mathrm{~ms}$, $0.05 \mathrm{~Hz}$ ) injected via the recording electrode. Application of drugs was made via the bath perfusion system or locally by pressure ejection from a broken pipette (approximately 5 - $\mu \mathrm{m}$ tip) positioned approximately $50 \mu \mathrm{m}$ above the recorded neuron at the concentrations indicated.

MRI and magnetic resonance spectroscopy. Mice were scanned using a 4.7T Varian system under isoflurane anesthesia. Whole-body images (between 50 and 60 slices; $2 \mathrm{~mm}$ thick) were obtained for each mouse using a spinecho sequence (TR4500/TE20). Semiautomatic image segmentation software (sliceOmatic version 4.2; Tomovision) was used to separate and quantify tissue volumes (37). For adipose tissue, the volume was multiplied by a correction factor of 0.9 in order to account for hydration (38).

Statistical analysis. All statistics were performed using GraphPad Prism 4 software and paired and unpaired Student's $t$ tests and 2-way ANOVA, with Bonferroni post-hoc tests performed as appropriate.

\section{Acknowledgments}

We thank Jonathan Godwin for blastocyst injections, Corinne Lobe for providing ZEG mice, Marika Charalambous for advice and discussion, Steven Lingard for technical assistance, and Andrew Tinker and Matthew Glyn for assistance with confo- 
cal microscopy. We thank the Biological Imaging Centre (BIC), Imaging Sciences Department, Imperial College London, for assistance with the MRI studies. The work was supported by grants from the Wellcome Trust (to A. Choudhury, C. Selman, M.A. Smith, M. Simmgen, K. Hisadome, M.L.J. Ashford, and D.J. Withers); the Biotechnology and Biological Sciences Research Council (BBSRC) (to M. Claret); the Medical Research Council (MRC; to H. Al-Qassab, I. Diakonov, J.D. Bell, R.L. Batterham, and D.J. Withers); Diabetes UK (to A. Choudhury and D.C. Bedford); the NIH (DK-48506, to G.S. Barsh); the Stanford Bio-X Interdisciplinary Initiatives Program (to G.S. Barsh); and by an AstraZeneca BBSRC CASE award (to H. Heffron). Part of this work was conducted within the BetaCellTherapy consortium that is supported as an integrated project by the sixth European
Union-framework program. R.L. Batterham is an MRC Clinician Scientist. D.J. Withers is an MRC Senior Clinical Fellow.

Received for publication January 10, 2005, and accepted in revised form February 22, 2005.

Address correspondence to: Dominic Withers, Centre for Diabetes and Endocrinology, Rayne Institute, University College London, 5 University Street, London WC1E 6JJ, United Kingdom. Phone: 44-20-7679-6586; Fax: 44-20-7679-6211; E-mail: d.withers@ucl.ac.uk.

Agharul I. Choudhury, Helen Heffron, Mark A. Smith, and Hind Al-Qassab contributed equally to this work.
1. DeFronzo, R.A. 1997. Pathogenesis of type 2 diabetes: metabolic and molecular implications for identifying diabetes genes. Diabetes Rev. 5:177-268.

2. Kulkarni, R.N., et al. 1999. Tissue-specific knockout of the insulin receptor in pancreatic beta cells creates an insulin secretory defect similar to that in type 2 diabetes. Cell. 96:329-339.

3. Woods, S.C., Lotter, E.C., McKay, L.D., and Porte, D., Jr. 1979. Chronic intracerebroventricular infusion of insulin reduces food intake and body weight of baboons. Nature. 282:503-505.

4. Bruning, J.C., et al. 2000. Role of brain insulin receptor in control of body weight and reproduction. Science. 289:2122-2125.

5. Obici, S., Feng, Z., Karkanias, G., Baskin, D.G., and Rossetti, L. 2002. Decreasing hypothalamic insulin receptors causes hyperphagia and insulin resistance in rats. Nat. Neurosci. 5:566-572.

6. Air, E.L., et al. 2002. Small molecule insulin mimetics reduce food intake and body weight and prevent development of obesity. Nat. Med. 8:179-183.

7. Withers, D.J. 2001. Insulin receptor substrate proteins and neuroendocrine function. Biochem. Soc. Trans. 29:525-529.

8. Tamemoto, H., et al. 1994. Insulin resistance and growth retardation in mice lacking insulin receptor substrate-1. Nature. 372:182-186.

9. Araki, E., et al. 1994. Alternative pathway of insulin signalling in mice with targeted disruption of the IRS-1 gene. Nature. 372:186-190.

10. Withers, D.J., et al. 1998. Disruption of IRS-2 causes type 2 diabetes in mice. Nature. 391:900-904.

11. Burks, D.J., et al. 2000. IRS-2 pathways integrate female reproduction and energy homeostasis. Nature. 407:377-382.

12. Suzuki, R., et al. 2004. Both insulin signaling defects in the liver and obesity contribute to insulin resistance and cause diabetes in Irs2(-/-) mice. J. Biol. Chem. 279:25039-25049.

13. Lin, X., et al. 2004. Dysregulation of insulin receptor substrate 2 in $\beta$ cells and brain causes obesity and diabetes. J. Clin. Invest. 114:908-916. doi:10.1172/JCI200422217.

14. Kubota, N., et al. 2004. Insulin receptor substrate 2 plays a crucial role in $\beta$ cells and the hypothala- mus. J. Clin. Invest. 114:917-927. doi:10.1172/ JCI200421484.

15. Brady, M.J. 2004. IRS2 takes center stage in the development of type 2 diabetes. J. Clin. Invest. 114:886-888. doi:10.1172/JCI200423108.

16. Novak, A., Guo, C., Yang, W., Nagy, A., and Lobe, C.G. 2000. Z/EG, a double reporter mouse line that expresses enhanced green fluorescent protein upon Cre-mediated excision. Genesis. 28:147-155.

17. Soriano, P. 1999. Generalized lacZ expression with the ROSA26 Cre reporter strain. Nat. Genet. 21:70-71.

18. Delacour, A., Nepote, V., Trumpp, A., and Herrera, P.L. 2004. Nestin expression in pancreatic exocrine cell lineages. Mech. Dev. 121:3-14.

19. Kubota, N., et al. 2000. Disruption of insulin receptor substrate 2 causes type 2 diabetes because of liver insulin resistance and lack of compensatory beta-cell hyperplasia. Diabetes. 49:1880-1889.

20. Dor, Y., Brown, J., Martinez, O.I., and Melton, D.A. 2004. Adult pancreatic beta-cells are formed by self-duplication rather than stem-cell differentiation. Nature. 429:41-46.

21. Cowley, M.A., et al. 2001. Leptin activates anorexigenic POMC neurons through a neural network in the arcuate nucleus. Nature. 411:480-484.

22. Withers, D.J., et al. 1999. Irs-2 coordinates Igf-1 receptor-mediated beta-cell development and peripheral insulin signalling. Nat. Genet. 23:32-40.

23. Balthasar, N., et al. 2004. Leptin receptor signaling in POMC neurons is required for normal body weight homeostasis. Neuron. 42:983-991.

24. Leibiger, I.B., Leibiger, B., Moede, T., and Berggren, P.O. 1998. Exocytosis of insulin promotes insulin gene transcription via the insulin receptor/PI-3 kinase/p70 s6 kinase and CaM kinase pathways. Mol. Cell. 1:933-938.

25. Kulkarni, R.N., et al. 1999. Altered function of insulin receptor substrate-1-deficient mouse islets and cultured beta-cell lines. J. Clin. Invest. 104:R69-R75.

26. Zulewski, H., et al. 2001. Multipotential nestin-positive stem cells isolated from adult pancreatic islets differentiate ex vivo into pancreatic endocrine, exocrine, and hepatic phenotypes. Diabetes. 50:521-533.
27. Lumelsky, N., et al. 2001. Differentiation of embryonic stem cells to insulin-secreting structures similar to pancreatic islets. Science. 292:1389-1394.

28. Treutelaar, M.K., et al. 2003. Nestin-lineage cells contribute to the microvasculature but not endocrine cells of the islet. Diabetes. 52:2503-2512.

29. Tobe, K., et al. 2001. Increased expression of the sterol regulatory element-binding protein-1 gene in insulin receptor substrate-2(-/-) mouse liver. J. Biol. Chem. 276:38337-38340.

30. Marsh, D.J., et al. 1999. Response of melanocortin-4 receptor-deficient mice to anorectic and orexigenic peptides. Nat. Genet. 21:119-122.

31. Kaelin, C.B., Xu, A.W., Lu, X.Y., and Barsh, G.S. 2004. Transcriptional regulation of agouti-related protein (Agrp) in transgenic mice. Endocrinology. 145:5798-5806.

32. Roseberry, A.G., Liu, H., Jackson, A.C., Cai, X., and Friedman, J.M. 2004. Neuropeptide Y-mediated inhibition of proopiomelanocortin neurons in the arcuate nucleus shows enhanced desensitization in ob/ob mice. Neuron. 41:711-722.

33. Postic, C., et al. 1999. Dual roles for glucokinase in glucose homeostasis as determined by liver and pancreatic beta cell-specific gene knock-outs using Cre recombinase. J. Biol. Chem. 274:305-315.

34. Tronche, F., et al. 1999. Disruption of the glucocorticoid receptor gene in the nervous system results in reduced anxiety. Nat. Genet. 23:99-103.

35. Xu, A.W., et al. 2005. PI3K integrates the action of insulin and leptin on hypothalamic neurons. J. Clin. Invest. 115:951-958. doi:10.1172/JCI200524301.

36. Livak, K.J., and Schmittgen, T.D. 2001. Analysis of relative gene expression data using real-time quantitative PCR and the 2(-Delta Delta C(T)) Method. Methods. 25:402-408.

37. Ross, R., Leger, L., Guardo, R., De Guise, J., and Pike, B.G. 1991. Adipose tissue volume measured by magnetic resonance imaging and computerized tomography in rats. J. Appl. Physiol. 70:2164-2172.

38. Tang, H., Vasselli, J.R., Wu, E.X., Boozer, C.N., and Gallagher, D. 2002. High-resolution magnetic resonance imaging tracks changes in organ and tissue mass in obese and aging rats. Am. J. Physiol. Regul. Integr. Comp. Physiol. 282:R890-R899. 